\title{
COMPARAÇÃO DOS PARÂMETROS FITOSSOCIOLÓGICOS ENTRE TRÊS ESTRATOS DE UM FRAGMENTO DE FLORESTA OMBRÓFILA MISTA
}

\author{
Sebastião do Amaral Machado ${ }^{1 *}$, Naiara Teodoro Zamin ${ }^{1}$, Rodrigo Geroni Mendes Nascimento', \\ Alan Lessa Derci Augustynczik ${ }^{1}$, Caroline Sanches Menegazzo ${ }^{2}$
}

*Autor para correspondência: samachado@ufpr.br

\begin{abstract}
RESUMO: Estudos fitossociológicos baseados em amostragem têm sido muito comuns ao longo dos últimos 20 anos, no entanto, são raramente realizados usando a enumeração completa das árvores (censo). Assim sendo, nesta pesquisa, objetivou-se comparar os parâmetros fitossociológicos entre os três diferentes estratos de um fragmento de Floresta Ombrófila Mista (FOM), quais sejam: FOM Montana, FOM Montana de Bordadura e FOM Aluvial. Essa área de 13,71 ha foi topograficamente dividida em blocos de 50 x 50 metros para melhor controle do inventário florestal a $100 \%$ (censo). Todas as árvores com CAP (circunferência medida a $1,30 \mathrm{~m}$ do solo) $\geq 31,5 \mathrm{~cm}$ foram medidas, georreferenciadas, numeradas, pintadas no DAP e identificadas em nível de espécie. No estrato FOM Montana, a espécie com maior valor de cobertura (VC) foi Araucaria angustifolia, com 30,6\%, seguida de Casearia sylvestris com 25,8\%. Já, na FOM Montana de Bordadura a espécie que procedeu a Araucaria angustifolia (29,0\%), foi Gochnatia polymorpha com $27,2 \%$ de VC. O terceiro estrato, FOM Aluvial, apresentou como espécie predominante Schinus terebinthifolius $(55,5 \%)$, seguida por Sebastiania commersoniana $(27,7 \%)$, ambas, características de ambientes aluvionares. Dessa maneira, o estudo permitiu observar que nos três estratos houve a predominância de espécies secundárias de caráter pioneiro, comprovando que a área em questão encontra-se em um estágio secundário de sucessão ecológica em razão de um processo exploratório no passado.
\end{abstract}

Palavras-chave: Censo, floresta secundária, valor de cobertura, dominância relativa.

\section{COMPARISON OF PHYTOSOCIOLOGICAL PARAMETERS AMONG THREE STRATA OF A FRAGMENT OF OMBROPHYLOUS MIXED FOREST}

\begin{abstract}
Phytosociological studies based on sampling have been very common in the last 20 years, however, they are rarely carried out using complete enumeration of trees (census). This research compare the phytossociological parameters between three different strata from a remnant of Ombrophylous Mixed Forest (OMF), which are: OMF Montana, Border OMF Montana and OMF Alluvial. The area of 13.71 was topographically divided in blocks of $50 \times 50$ meters for a better control of the $100 \%$ forest inventory (census). All trees with $\mathrm{CBH}$ (circumference measured at 1,30 m above ground) $\geq 31,5$ centimeters were measured, georeferencied, numbered, painted at DBH and identified at species level. In the strata OMF Montana the species with the highest Value of Coverage (VC) was Araucaria angustifolia, with 30.6\%, followed by Casearia sylvestris with 25.8\%. In the Border OMF Montana the species that succeeded Araucaria angustifolia (29.0\%) was Gochnatia polymorpha with 27.2\% of VC. The third strata, OMF Alluvial, presented as predominant species Schinus terebinthifolius (55,5\%), followed by Sebastiania commersoniana (27,7\%), both characteristics of alluvial environments. In the three strata there was prevalence of secondary pioneer species, proving that the area is in a secondary stage of ecological succession due to past exploratory process.
\end{abstract}

Key words: Census, secondary forest, value of coverage, relative dominance.

\section{INTRODUÇÃO}

A Floresta Ombrófila Mista possui significativa importância dentre as unidades fitogeográficas brasileiras. Em razão do interesse por extração de madeira e pela expansão das fronteiras agrícolas, essa formação florestal sofreu forte exploração, reduzindo-a a apenas 1 a $2 \%$ da sua área original (KOCH; CORRÊA, 2002). No entanto, pelas restrições impostas pela legislação ambiental, atualmente a exploração vem diminuído, o que gera a necessidade de estudos que visem ao entendimento da dinâmica e desenvolvimento da floresta (IURK et al., 2009). Tais estudos propiciam a obtenção de informações adequadas

${ }^{1}$ Universidade Federal do Paraná - Curitiba, Paraná, Brasil

${ }^{2}$ GRANFLOR - São Gabriel, Rio Grande do Sul, Brasil para o planejamento de atividades de preservação de fragmentos florestais.

Levantamentos florísticos e fitossociológicos são amplamente utilizados atualmente para o monitoramento da regeneração natural, quantificação das espécies presentes na área, estratificação vegetal, entre outras atividades que fornecem subsídios para estudos relacionados à preservação e recuperação de áreas (IURK et al., 2009).

Segundo Kozera et al. (2006), apesar de vários trabalhos sistematizados de levantamento florístico e/ou fitossociológico terem sido realizados no Brasil em áreas com FOM, ainda são necessários estudos dos remanescentes dessa unidade, principalmente com relação

Cerne, Lavras, v. 19, n. 3, p. 365-372, jul./set. 2013 
às espécies presentes na floresta e a forma como se distribuem na comunidade. Para esses autores, trabalhos dessa natureza contribuem para o conhecimento das características do ecossistema e podem subsidiar diferentes tipos de projetos, como, por exemplo, os de recuperação de áreas degradadas, auxiliando na seleção das espécies para a realização de plantios.

A estratificação da vegetação é utilizada quando se tem uma população muito heterogênea e deseja-se subdividi-la em subpopulações mais homogêneas, a fim de facilitar na gestão de informações da floresta (SANQUETTA et al., 2009). Esses autores ainda classificam como estratificação tipológica aquela que tem como objetivo obter informações particulares de cada tipo florestal, sendo, geralmente, aplicada em florestas nativas. Por conseguinte, essa estratificação torna-se uma ferramenta de grande aplicabilidade em estudos fitossociológicos.

O Capão da Engenharia Florestal constitui um bom exemplo de fragmentos de Floresta Ombrófila Mista de regeneração natural secundária ocorrida após explorações florestais, no fim do século 19, e, principalmente, na primeira metade do século 20. Esses fragmentos se distribuem por toda a região sul do Brasil, em tamanhos e formas variadas. Como todos os fragmentos dessa tipologia florestal, o Capão da Engenharia Florestal não é homogêneo em sua extensão, constituindo-se de três estratos diferenciados, quais sejam a Floresta Ombrófila Mista Montana, a Floresta Ombrófila Mista Aluvial e a Floresta Ombrófila Mista Montana de Bordadura.

Muitas pesquisas sobre fitossociologia e estrutura têm sido feitas em fragmentos dessa tipologia florestal (RONDON NETO et al., 2002). No entanto, nenhuma delas baseou-se em inventário a $100 \%$ (censo), permitindo a obtenção de parâmetros observados e não estimados como em casos em que se usa medir apenas unidades amostrais distribuídas no interior da floresta. Com a importância de se obter conhecimentos fitossociológicos adequados para o planejamento de preservação, conservação e recuperação dos fragmentos florestais, este estudo teve como objetivo comparar os parâmetros fitossociológicos entre três diferentes estratos de um fragmento de Floresta Ombrófila Mista, possibilitando, desta forma, um melhor entendimento da dinâmica desse remanescente.

\section{MATERIAL E MÉTODOS}

\section{1 Área de estudo e coleta de dados}

O presente estudo foi realizado em um fragmento de Floresta Ombrófila Mista, conhecido como Capão da
Engenharia Florestal, o qual está localizado no Campus III da Universidade Federal do Paraná, Jardim Botânico, Curitiba - PR.

A área encontra-se sob as coordenadas geográficas

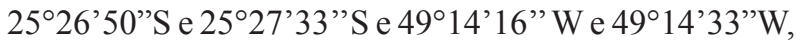
com altitude média de 900 metros. A área total do capão é de 13,71 ha.

O clima da região, segundo a classificação de Köppen é predominantemente $\mathrm{Cfb}$, subtropical úmido mesotérmico, caracterizado por verões frescos, invernos com geadas frequentes e chuvas bem distribuídas ao longo do ano. As temperaturas médias anuais nos meses mais quentes são de $22^{\circ} \mathrm{C}$ e nos mais frios abaixo de $18^{\circ} \mathrm{C}$, tendo como média anual $17^{\circ} \mathrm{C}$. A precipitação média anual chega a $1500 \mathrm{~mm}$, distribuída no ano inteiro.

Os dados utilizados nesta pesquisa provieram de 8988 árvores, mensuradas no censo do Capão. Para tanto, a área foi dividida em blocos de $50 \times 50$ metros, sendo medida a circunferência a 1,30m (CAP) de todos os indivíduos com $\mathrm{CAP} \geq 31,5 \mathrm{~cm}$. Cada árvore foi georreferenciada, recebeu uma plaqueta com sua numeração e foi identificada em nível de espécie e família.

\subsection{Análise dos dados}

O Capão da Engenharia Florestal foi subdivido em três estratos florestais, definidos de acordo com comportamentos texturais, espectrais e de composição florística identificados em imagem aérea e em campo.

Primeiramente, identificou-se um estrato aluvial, pela presença de um córrego na porção sul do fragmento, apresentando composição florística diferenciada em termos estruturais, conforme descrito por Roderjan et al. (2002). Esse estrato foi classificado como Floresta Ombrófila Mista Aluvial e sua delimitação ocorreu por meio de imagem aérea e confirmação em campo quando da realização do censo.

A porção central que ocupa a maior parte do fragmento florestal estudado, foi classificada como Floresta Ombrófila Mista Montana, a qual é caracterizada pela ocorrência da espécie Araucaria angustifolia (Bert.) O. Kuntze, bem como pela altitude em que se encontra no primeiro planalto paranaense.

$\mathrm{O}$ ultimo estrato foi denominado como Floresta Ombrófila Mista Montana de Bordadura, pelas suas características de FOMM e de ambientes de bordadura florestal que apresentam grande número de espécies pioneiras, conforme classificação utilizada por Carvalho (2003), com estrutura horizontal de menor amplitude

Cerne, Lavras, v. 19, n. 3, p. 365-372, jul./set. 2013 
diamétrica, assim como formado por apenas dois estratos verticais, sendo o primeiro dominado por araucárias e o segundo pelas demais espécies. Nas imagens aéreas, pode-se perceber menor densidade de copas nessa porção, auxiliando na delimitação dessa subtipologia.

Pela identificação desses diferentes estratos, a análise fitossociológica foi realizada individualmente para cada um deles. Com base no censo, foi determinado o número verdadeiro de árvores por espécie por hectare (densidade absoluta) e o referido valor em percentagem (densidade relativa), a área basal por espécie por hectare (dominância absoluta) e também seu valor expresso em porcentagem (dominância relativa). A obtenção desses resultados permitiu o cálculo do valor de cobertura (VC), que é a somatória de dominância relativa com densidade relativa. Determinaram-se também os valores médios de diâmetro e área transversal e a soma da área basal.

\section{RESULTADOS E DISCUSSÃO}

A divisão da área em três estratos possibilitou a identificação de três tipologias no local: Floresta Ombrófila Mista Montana, com 8,97 hectares, Floresta Ombrófila Mista Montana de Bordadura, com 2,64 hectares e Floresta Ombrófila Mista Aluvial com 2,1 hectares, perfazendo um total de 13,71 hectares.

Apesar da grande variedade de espécies encontradas nos três estratos avaliados, somente os parâmetros fitossociológicos das vinte espécies de maior VC foram apresentados, visando a maior objetividade e redução na extensão das tabelas.

\subsection{Floresta Ombrófila Mista Montana}

Esse estrato representa a maior área do capão, quando comparado aos demais estratos, ocupando, aproximadamente, $65 \%$ da área total. Encontrou-se, nesse estrato, grande variabilidade e distribuição de espécies, contudo, duas espécies apresentaram maior representatividade. Isso se deve a alta densidade de indivíduos com pequenos diâmetros, característica típica de florestas secundárias.

O número total de indivíduos, neste estrato, foi de 6822, contabilizando 761 árvore por hectare, distribuídos em 110 espécies, 80 gêneros e 43 famílias. As espécies de maior relevância foram, Araucaria angustifolia e Casearia sylvestris, apresentando valores de cobertura, respectivamente de $30,6 \%$ e $25,8 \%$. Na Tabela 1 , apresentam-se, em ordem decrescente, as 20 espécies com maior valor de cobertura.
Rondon Neto et al. (2002) realizaram um estudo fitossociológico nesse mesmo fragmento de Floresta Ombrófila Mista, implantando 18 parcelas de 10 X $20 \mathrm{~m}$. Após análises, verificaram que as espécies de maior valor de cobertura foram: Allophylus edulis $(25,47 \%)$, Casearia sylvestris $(24,83 \%)$, Luehea divaricata (22,17\%), Araucaria angustifolia (19,76\%), Ocotea corymbosa (8,27\%), Cupania vernalis $(7,72 \%)$, Ocotea nutans $(6,49 \%)$, Mollinedia clavigera $(4,96 \%)$ e Jacaranda puberula $(4,49 \%)$.

Comparando-se os resultados obtidos por meio de amostragem por Rondon Neto et al. (2002) com o inventário $100 \%$ realizado neste estudo, pode-se observar que quase a totalidade das espécies apresentaram valores estimados médios de valor de cobertura, bem diferentes dos seus respectivos valores paramétricos, apresentados na Tabela 1, exceto a Casearia sylvestris com valores semelhantes de VC para ambos os estudos. Foi observado também que, a área basal $\left(37,08 \mathrm{~m}^{2} / \mathrm{ha}\right)$, o diâmetro médio $(11,6 \mathrm{~cm})$ e o número de indivíduos por hectare (1.972 ind./ha) encontrados por Rondon Neto et al. (2002) diferenciaram dos valores reais encontrados no censo (Tabela 1).

Rivera et al. (2009) instalaram 48 parcelas de $500 \mathrm{~m}^{2}$ e oito de $250 \mathrm{~m}^{2}$ visando a determinar a estrutura fitossociológica do estrato arbóreo de uma Floresta Ombrófila Mista localizada em Caçador, SC. Esses autores encontraram 71 espécies, 54 gêneros e 33 famílias, as quais representaram uma densidade de 483,6 indivíduos por hectare. As espécies que apresentaram maior densidade absoluta foram Cupania vernalis $(75$ indivíduos/ha), seguida por Araucaria angustifolia, Matayba elaeagnoides, Capsicodendron dinisii, Prunus brasiliensis e Ocotea pulchella com 20 a 30 indivíduos/ha. Já, no presente estudo, essas espécies apresentaram valores de densidade absoluta inferiores aos observados por Rivera et al. (2009), coincidindo apenas a espécie Araucaria angustifolia.

Dados fitossociológicos provenientes de 74 unidades amostrais instalados no Inventário Florestal do estado de Santa Catarina na Floresta Ombrófila Mista apresentados por Vibrans et al. (2008), mostraram que as cinco espécies de maior $\mathrm{VC}$ em ordem decrescente foram: Araucaria angustifolia (30,14\%), Myrceugenia euosma (14,77\%), Dicksonia sellowiana (14,60\%), Cinnamomum amoemum (11,06\%), Lithraea brasiliensis $(8,75 \%)$. Esses valores divergem muito dos encontrados na presente pesquisa, com exceção da Araucaria angustifolia como se vê na Tabela 1.

Cerne, Lavras, v. 19, n. 3, p. 365-372, jul./set. 2013 
Tabela 1 - Valores fitossociológicos das 20 espécies de maior VC da Floresta Ombrófila Mista Montana.

Table 1 - Phytossociological values of the 20 species with the highest VC of the Ombrophylous Mixed Montana Forest.

\begin{tabular}{|c|c|c|c|c|c|c|c|c|c|}
\hline Espécies & $\begin{array}{c}\mathrm{N} \\
\text { (árv) }\end{array}$ & $\begin{array}{c}\text { DA } \\
(\mathrm{N} / \mathrm{ha})\end{array}$ & $\begin{array}{l}\mathrm{DR} \\
(\%)\end{array}$ & $\begin{array}{l}\text { DAP } \\
(\mathrm{cm})\end{array}$ & $\underset{\left(\mathrm{m}^{2}\right)}{\mathrm{g}}$ & $\begin{array}{c}\mathrm{G} \\
\left(\mathrm{m}^{2}\right)\end{array}$ & $\begin{array}{c}\text { DoA } \\
\left(\mathrm{m}^{2} / \mathrm{ha}\right)\end{array}$ & $\begin{array}{c}\text { DoR } \\
(\%)\end{array}$ & $\begin{array}{l}\mathrm{VC} \\
(\%)\end{array}$ \\
\hline Araucaria angustifolia (Bert.) O. Kuntze & 255 & 28,4 & 3,7 & 53,6 & 0,226 & 57,62 & 6,42 & 26,9 & 30,6 \\
\hline Casearia sylvestris $\mathrm{Sw}$. & 1195 & 133,2 & 17,5 & 13,7 & 0,015 & 17,68 & 1,97 & 8,2 & 25,8 \\
\hline Luehea divaricata Mart. Et Zucc & 555 & 61,9 & 8,1 & 19,6 & 0,030 & 16,73 & 1,86 & 7,8 & 15,9 \\
\hline Ocotea puberula (Rich.) Nees & 329 & 36,7 & 4,8 & 22,9 & 0,041 & 13,56 & 1,51 & 6,3 & 11,1 \\
\hline Symplocos tetrandra (Mart.) Miq. & 320 & 35,7 & 4,7 & 18,3 & 0,026 & 8,37 & 0,93 & 3,9 & 8,6 \\
\hline Myrcia hatschbachii D. Legrand & 235 & 26,2 & 3,4 & 21,7 & 0,037 & 8,69 & 0,96 & 4,1 & 7,5 \\
\hline Jacaranda puberula Cham. & 316 & 35,2 & 4,6 & 15,0 & 0,018 & 5,57 & 0,62 & 2,6 & 7,2 \\
\hline Casearia obliqua Spreng. & 286 & 31,9 & 4,2 & 14,6 & 0,017 & 4,81 & 0,53 & 2,2 & 6,4 \\
\hline Cedrela fissilis Vell. & 176 & 19,6 & 2,6 & 23,8 & 0,044 & 7,84 & 0,87 & 3,7 & 6,2 \\
\hline $\begin{array}{l}\text { Allophylus edulis (A. St.-Hil., A. Juss. \& } \\
\text { Cambess.) Hieron. ex Niederl. }\end{array}$ & 274 & 30,5 & 4,0 & 13,1 & 0,013 & 3,69 & 0,41 & 1,7 & 5,7 \\
\hline Ocotea nutans (Nees) Mez. & 182 & 20,3 & 2,7 & 17,6 & 0,024 & 4,43 & 0,49 & 2,1 & 4,7 \\
\hline Nectandra lanceolata Nees & 128 & 14,3 & 1,9 & 21,4 & 0,036 & 4,58 & 0,51 & 2,1 & 4,0 \\
\hline Ocotea bicolorVattimo & 142 & 15,8 & 2,1 & 17,8 & 0,025 & 3,54 & 0,39 & 1,7 & 3,7 \\
\hline Cupania vernalis Cambess. & 166 & 18,5 & 2,4 & 12,4 & 0,012 & 2,01 & 0,22 & 0,9 & 3,4 \\
\hline Matayba elaeagnoides Radlk. & 125 & 13,9 & 1,8 & 17,7 & 0,025 & 3,07 & 0,34 & 1,4 & 3,3 \\
\hline Capsicodendron dinisii (Schwacke) Occhioni & 71 & 7,9 & 1,0 & 28,4 & 0,063 & 4,50 & 0,50 & 2,1 & 3,1 \\
\hline Myrcia rostrata DC. & 137 & 15,3 & 2,0 & 14,5 & 0,017 & 2,26 & 0,25 & 1,1 & 3,1 \\
\hline Clethra scabra Pers, & 106 & 11,8 & 1,6 & 17,5 & 0,024 & 2,56 & 0,28 & 1,2 & 2,7 \\
\hline Piptocarpha axillaris (Less.) Baker & 73 & 8,1 & 1,1 & 22,5 & 0,040 & 2,89 & 0,32 & 1,3 & 2,4 \\
\hline Sloanea monosperma Vell. & 46 & 5,1 & 0,7 & 29,9 & 0,070 & 3,23 & 0,36 & 1,5 & 2,2 \\
\hline Demais espécies & 98 & 190,1 & 25,0 & 17,6 & 0,029 & 36,71 & 4,09 & 17,1 & 42,1 \\
\hline Total & 6822 & 760,5 & 100 & 18,3 & 0,035 & 214,4 & 23,9 & 100 & 200 \\
\hline
\end{tabular}

Legenda: N: Número de árvores; DA: Densidade Absoluta; DR: Densidade Relativa; DAP: DAP médio; g $\left(\mathrm{m}^{2}\right)$ : área tranversal média; $\mathrm{G}\left(\mathrm{m}^{2}\right)$ : Área Basal Total; DoA: Dominância Absoluta; DoR: Dominância Relativa; VC: Valor de Cobertura.

Legend: N: Number of trees; DA: Absolute Density; DR: Relative Density; DAP: Average DBH; $g\left(m^{2}\right)$ : average cross sectional area; $G\left(m^{2}\right)$ : basal area; DoA: Absolute Dominance; DoR: Relative Dominance; VC: Value of Coverage.

Klauberg et al. (2010), realizando uma análise florística e fitossociológica no Parque Natural Municipal João José Theodoro da Costa Neto - em Lages, SC a partir da instalação de quatro parcelas de 40 x 40m, encontraram 46 espécies, 39 gêneros e 27 famílias botânicas, números estes muito inferiores ao observado na presente pesquisa, possivelmente em razão da menor variabilidade captada pela amostragem. Algumas espécies observadas por esses autores merecem destaque pelo grande número de indivíduos por hectare, tais como Casearia decandra (236,82 ind./ha), Dicksonia sellowiana (224,61 ind./ha), Blepharocalyx salicifolius $(153,81$ ind./ha), Cupania vernalis (134,28 ind./ha), Allophylus edulis (131,84 ind./ha), Clethra scabra (126,95 ind./ha), Matayba elaeagnoides (109,86 ind./ha) e Campomanesia xanthocarpa (90,33 ind./ha), algumas delas também destacadas na presente pesquisa, conforme apresentado na Tabela 1.

Silva et al. (2012) realizaram uma análise fitosociológica, a partir de 25 parcelas alocadas em um fragmento de Floresta Ombrófila Mista Montana de 22 ha, localizado em Lages, SC. Esses autores encontraram VC para A. angustifolia de $24,28 \%$, sendo semelhante ao encontrado no presente trabalho, contudo o mesmo não ocorreu para algumas das espécies com elevado valor de cobertura observadas, como Podocarpus

Cerne, Lavras, v. 19, n. 3, p. 365-372, jul./set. 2013 
lambertii (14,52\%), Myrcia splendens (11,73\%), Matayba elaeagnoides (10,95\%), Zanthoxylum kleinii (10,38\%), Ocotea pulchella $(10,19 \%)$, as quais não estão listadas nem mesmo entre as 20 primeiras, conforme Tabela 1.

Essa diferença de resultados de diversas pesquisas com o presente trabalho, todos feitos em Floresta Ombrófila Mista, pode ser em decorrência, parcialmente, das diferenças naturais existentes em diversas localidades.

\subsection{Floresta Ombrófila Mista Montana de Bordadura}

Esse estrato representa 19,3\% da área inventariada, no qual foram medidos 2093 indivíduos arbóreos, com média de 791 indivíduos por hectare, tendo sido identificadas 83 espécies, 64 gêneros e 42 famílias. Os parâmetros fitossociológicos encontrados estão apresentados na Tabela 2.
Observou-se que essa tipologia florestal apresentou menor número de espécies, gêneros e de famílias arbóreas quando comparada aos valores encontrados para a FOM Montana, de estágio secundário inicial. Klauberg et al. (2010) descreveram que o efeito de borda decorrente da fragmentação pode modificar a fisionomia da vegetação.

A Araucaria angustifolia foi a espécie que apresentou maior $\mathrm{VC}$, sendo a grande dimensão das árvores representada pela dominância relativa, fator determinante nesse resultado, já que contribui com maior parte do VC. Kozera et al. (2006) também apresentaram a $A$. angustifolia como destaque no grupo das espécies de maior porte com elevados valores de dominância e, consequentemente, de Valor de Cobertura, refletindo o grande porte dos indivíduos, comparativamente aos das demais espécies.

Tabela 2 - Valores fitossociológicos das 20 espécies de maior VC da Floresta Ombrófila Mista Montana de Bordadura.

Table 2 - Phytossociological values of the 20 species with the highest VC of the Border Ombrophylous Mixed Montana Forest.

\begin{tabular}{|c|c|c|c|c|c|c|c|c|c|}
\hline Espécie & $\begin{array}{c}\mathrm{N} \\
\text { (árv) }\end{array}$ & $\begin{array}{c}\text { DA } \\
(\mathrm{N} / \mathrm{ha})\end{array}$ & $\begin{array}{l}\text { DR } \\
(\%)\end{array}$ & $\begin{array}{l}\text { DAP } \\
(\mathrm{cm})\end{array}$ & $\begin{array}{c}\mathrm{g} \\
\left(\mathrm{m}^{2}\right)\end{array}$ & $\begin{array}{c}\mathrm{G} \\
\left(\mathrm{m}^{2}\right)\end{array}$ & $\begin{array}{c}\text { DoA } \\
\left(\mathrm{m}^{2} / \mathrm{ha}\right)\end{array}$ & $\begin{array}{c}\text { DoR } \\
(\%)\end{array}$ & $\begin{array}{l}\mathrm{VC} \\
(\%)\end{array}$ \\
\hline Araucaria angustifolia & 77 & 29,1 & 3,7 & 49,7 & 0,194 & 14,95 & 5,65 & 25,3 & 29,0 \\
\hline Gochnatia polymorpha (Less.) Cabrera & 261 & 98,7 & 12,5 & 20,6 & 0,033 & 8,70 & 3,29 & 14,7 & 27,2 \\
\hline Luehea divaricata & 186 & 70,3 & 8,9 & 15,8 & 0,020 & 3,64 & 1,38 & 6,2 & 15,0 \\
\hline Symplocos tetrandra & 168 & 63,5 & 8,0 & 16,7 & 0,022 & 3,66 & 1,39 & 6,2 & 14,2 \\
\hline Casearia sylvestris & 188 & 71,1 & 9,0 & 13,2 & 0,014 & 2,57 & 0,97 & 4,4 & 13,3 \\
\hline Schinus terebinthifolius Raddi & 139 & 52,6 & 6,6 & 16,7 & 0,022 & 3,03 & 1,14 & 5,1 & 11,8 \\
\hline Jacaranda puberula & 135 & 51,1 & 6,5 & 14,7 & 0,017 & 2,31 & 0,87 & 3,9 & 10,3 \\
\hline Ocotea puberula & 64 & 24,2 & 3,1 & 22,5 & 0,040 & 2,54 & 0,96 & 4,3 & 7,4 \\
\hline Clethra scabra & 84 & 31,8 & 4,0 & 14,8 & 0,017 & 1,45 & 0,55 & 2,5 & 6,5 \\
\hline Matayba elaeagnoides & 69 & 26,1 & 3,3 & 15,6 & 0,019 & 1,31 & 0,49 & 2,2 & 5,5 \\
\hline Machaerium paraguariense Hassl. & 49 & 18,5 & 2,3 & 16,9 & 0,022 & 1,10 & 0,42 & 1,9 & 4,2 \\
\hline Dasyphyllum tomentosum (Spreng.) Cabrera & 38 & 14,4 & 1,8 & 19,3 & 0,029 & 1,12 & 0,42 & 1,9 & 3,7 \\
\hline Citronella gongonha (Mart.) R.A. Howard & 47 & 17,8 & 2,2 & 13,8 & 0,015 & 0,70 & 0,27 & 1,2 & 3,4 \\
\hline Cedrela fissilis & 25 & 9,5 & 1,2 & 23,8 & 0,044 & 1,11 & 0,42 & 1,9 & 3,1 \\
\hline Allophylus edulis & 41 & 15,5 & 2,0 & 12,8 & 0,013 & 0,52 & 0,20 & 0,9 & 2,8 \\
\hline Capsicodendron dinisii & 27 & 10,2 & 1,3 & 20,4 & 0,033 & 0,88 & 0,33 & 1,5 & 2,8 \\
\hline Zanthoxylum kleinii (R.S. Cowan) P.G. Waterman & 30 & 11,3 & 1,4 & 15,6 & 0,019 & 0,57 & 0,22 & 1,0 & 2,4 \\
\hline Ocotea nutans & 31 & 11,7 & 1,5 & 14,6 & 0,017 & 0,52 & 0,19 & 0,9 & 2,4 \\
\hline Symplocos uniflora (Pohl) Benth. & 27 & 10,2 & 1,3 & 14,3 & 0,016 & 0,43 & 0,16 & 0,7 & 2,0 \\
\hline Lithraea brasiliensis Marchand & 22 & 8,3 & 1,1 & 16,5 & 0,021 & 0,47 & 0,18 & 0,8 & 1,9 \\
\hline Demais espécies & 385 & 145,6 & 18,4 & 16,3 & 0,022 & 7,53 & 2,84 & 12,7 & 31,1 \\
\hline Total & 2093 & 791,5 & 100 & 17,7 & 0,031 & 59,14 & 22,37 & 100 & 200 \\
\hline
\end{tabular}

Cerne, Lavras, v. 19, n. 3, p. 365-372, jul./set. 2013 
A espécie Gochnatia polymorpha apresentou alta densidade, seu valor de cobertura se assemelha ao de Araucaria angustifolia, sendo igual a 27,2\%. Dessa forma, essas duas espécies juntas representam mais de $50 \%$ do VC total desse estrato. De acordo com as características fitoecológicas, Gochnatia polymorpha é de caráter pioneiro e adapta-se bem em ambientes degradados que, geralmente, são encontradas em locais de farta luminosidade, como as bordas das matas e capões (CARVALHO, 2003), justificando sua presença marcante neste estrato.

Também apresentaram alta densidade neste estrato as espécies: Casearia sylvestris, Symplocos tetrandra e Luehea divaricata. Essas espécies, se encontram entre as dez mais relevantes também na FOM Montana, contudo com VC diferenciados, com exceção da Luehea divaricata.

\subsection{Floresta Ombrófila Mista Aluvial}

Este estrato abrange uma área de 2,1 hectares $(15,3 \%)$ do total inventariado. Nele foi mensurado um total de 920 indivíduos, perfazendo 438 indivíduos por hectare, tendo sido identificadas 63 espécies, 46 gêneros e 31 famílias. Os parâmetros fitossociológicos encontrados estão apresentados na Tabela 3.

Essa tipologia apresentou menor número de espécies, gêneros e famílias comparativamente aos dois estratos anteriores; isto se deve às limitações ambientais, as quais esses indivíduos estão expostos, ou seja, solos com alto teor de umidade, geralmente arenoso, pela deposição constante de material pelo rio e por consequência com menores teores de fertilidade. Conforme Roderjan et al. (2002), essa unidade pode apresentar diferentes graus

Tabela 3 - Valores fitossociológicos das 20 espécies de maior VC da Floresta Ombrófila Mista Aluvial.

Table 3 - Phytossociological values of the 20 species with the highest VC of the Alluvial Ombrophylous Mixed Forest.

\begin{tabular}{|c|c|c|c|c|c|c|c|c|c|}
\hline Espécie & $\mathrm{N}$ & $\begin{array}{c}\text { DA } \\
(\mathrm{N} / \mathrm{ha})\end{array}$ & $\begin{array}{l}\text { DR } \\
(\%)\end{array}$ & $\begin{array}{l}\text { DAP } \\
(\mathrm{cm})\end{array}$ & $\begin{array}{c}\mathrm{g} \\
\left(\mathrm{m}^{2}\right)\end{array}$ & $\begin{array}{c}\mathrm{G} \\
\left(\mathrm{m}^{2}\right)\end{array}$ & $\begin{array}{c}\text { DoA } \\
\left(\mathrm{m}^{2} / \mathrm{ha}\right)\end{array}$ & $\begin{array}{c}\text { DoR } \\
(\%)\end{array}$ & $\begin{array}{l}\mathrm{VC} \\
(\%) \\
\end{array}$ \\
\hline Schinus terebinthifolius & 272 & 129,5 & 29,6 & 15,8 & 0,020 & 5,36 & 2,55 & 26,0 & 55,5 \\
\hline $\begin{array}{l}\text { Sebastiania commersoniana (Baill.) L.B. Sm. \& } \\
\text { Downs }\end{array}$ & 138 & 65,7 & 15,0 & 15,5 & 0,019 & 2,61 & 1,24 & 12,7 & 27,7 \\
\hline Ocotea puberula & 52 & 24,8 & 5,7 & 21,2 & 0,035 & 1,83 & 0,87 & 8,9 & 14,5 \\
\hline Clethra scabra & 39 & 18,6 & 4,2 & 15,3 & 0,018 & 0,72 & 0,34 & 3,5 & 7,7 \\
\hline Symplocos tetrandra & 27 & 12,9 & 2,9 & 20,1 & 0,032 & 0,86 & 0,41 & 4,2 & 7,1 \\
\hline Ligustrum lucidum W.T. Aiton & 28 & 13,3 & 3,0 & 17,6 & 0,024 & 0,68 & 0,32 & 3,3 & 6,3 \\
\hline Luehea divaricata & 21 & 10,0 & 2,3 & 18,6 & 0,027 & 0,57 & 0,27 & 2,8 & 5,0 \\
\hline Allophylus edulis & 28 & 13,3 & 3,0 & 13,4 & 0,014 & 0,39 & 0,19 & 1,9 & 4,9 \\
\hline Matayba elaeagnoides & 18 & 8,6 & 2,0 & 19,9 & 0,031 & 0,56 & 0,27 & 2,7 & 4,7 \\
\hline Escallonia montevidensis (Cham. \& Schltdl.) DC. & 27 & 12,9 & 2,9 & 12,6 & 0,012 & 0,34 & 0,16 & 1,6 & 4,6 \\
\hline Blepharocalyx salicifolius (Kunth) O. Berg & 21 & 10,0 & 2,3 & 16,7 & 0,022 & 0,46 & 0,22 & 2,2 & 4,5 \\
\hline Lithrea brasiliensis & 16 & 7,6 & 1,7 & 16,9 & 0,022 & 0,36 & 0,17 & 1,7 & 3,5 \\
\hline Araucaria angustifolia & 3 & 1,4 & 0,3 & 50,3 & 0,199 & 0,60 & 0,28 & 2,9 & 3,2 \\
\hline Lonchocarpus campestris Mart. ex Benth. & 13 & 6,2 & 1,4 & 18,0 & 0,025 & 0,33 & 0,16 & 1,6 & 3,0 \\
\hline Symplocos uniflora & 16 & 7,6 & 1,7 & 14,1 & 0,015 & 0,25 & 0,12 & 1,2 & 2,9 \\
\hline Não identificada 1 & 11 & 5,2 & 1,2 & 20,0 & 0,031 & 0,34 & 0,16 & 1,7 & 2,9 \\
\hline Myrcia hatschbachii D. Legrand & 13 & 6,2 & 1,4 & 15,9 & 0,020 & 0,26 & 0,12 & 1,3 & 2,7 \\
\hline Prunus brasiliensis (Cham. \& Schltdl.) D. Dietr. & 8 & 3,8 & 0,9 & 22,9 & 0,041 & 0,33 & 0,16 & 1,6 & 2,5 \\
\hline Lamanonia speciosa (Cambess.) L.B. Sm. & 10 & 4,8 & 1,1 & 18,8 & 0,027 & 0,28 & 0,13 & 1,3 & 2,4 \\
\hline Machaerium paraguariense & 13 & 6,2 & 1,4 & 13,9 & 0,015 & 0,20 & 0,09 & 1,0 & 2,4 \\
\hline Demais espécies & 146 & 69,5 & 15,9 & 17,2 & 0,027 & 3,31 & 1,58 & 16,1 & 32,0 \\
\hline Total & 920 & 438,1 & 100 & 16,6 & 0,024 & 20,64 & 9,83 & 100 & 200 \\
\hline
\end{tabular}

Cerne, Lavras, v. 19, n. 3, p. 365-372, jul./set. 2013 
de desenvolvimento, desde comunidades simplificadas pelo grau de hidromorfia dos solos - Neossolos Flúvicos e Gleissolos - onde predomina a espécie Sebastiania commersoniana, até associações mais complexas, onde a Araucaria angustifolia tem participação expressiva na composição florestal.

A espécie Schinus terebinthifolius apresentou o maior $\mathrm{VC}$, o qual foi influenciado, principalmente, pela sua elevada densidade relativa. Carvalho (2003) afirmou que essa espécie é frequente nas capoeiras das encostas e em beira de rios, ocorrendo nas formações Aluvial e Montana da FOM, justificando sua elevada presença nesse estrato. Além disso, Roderjan et al. (2002) apresentaram essa espécie como sendo importante integrante do dossel da FOM Aluvial.

Outra espécie de presença significativa nesse estrato foi a Sebastiania commersoniana. Essa espécie também é característica de áreas aluvionares, sendo citada por Roderjan et al. (2002) como sendo a mais frequente em ambientes com hidromorfia acentuada.

Iurk et al. (2009), em estudo florístico realizado na FOM Aluvial do Rio Iguaçú, no município de Palmeira (PR), encontraram 41 espécies, 33 gêneros e 20 famílias de indivíduos arbóreos, com predomínio de Sebastiania commersoniana, espécie que apareceu em todos os estratos verticais (superior, médio e inferior) em seu estudo.

Barddal et al. (2004) realizaram estudo florístico e fitossociológico de uma FOM aluvial no município de Araucária, PR. Nessa pesquisa esses autores encontraram solo do tipo Gleissolo, com predomínio da espécie Sebastiania commersoniana (branquilho) no estrato superior, a com valor de importância seis vezes superior ao da segunda espécie classificada, dominando a estrutura geral da vegetação.

Tendo em vista que as três tipologias analisadas encontram-se em um contínuo e fazem parte da mesma formação florestal caracterizada como Floresta Ombrófila Mista é de se esperar que várias das espécies, principalmente as generalistas, sejam comuns aos diversos estratos, conforme observado nas Tabelas 1, 2 e 3.

\section{CONCLUSÕES}

Com o cálculo e comparação dos índices fitossociológicos paramétricos dos três estratos do fragmento florestal estudado, concluiu-se que a FOM Montana e a FOM Montana de Bordadura possuem valores de DAP médio, N/ha e número de espécies similares entre si, porém maiores do que na FOM Aluvial.
A espécie $A$. angustifolia apresentou elevado valor de cobertura no estrato FOM Montana e FOM Montana de Bordadura, predominando nesses estratos.

No estrato FOM Montana, observou-se a presença marcante de espécies secundárias, já, na FOM Montana de Bordadura, algumas espécies pioneiras se destacaram.

A FOM Aluvial apresentou fisionomia diferenciada dos demais estratos avaliados, com menor variabilidade de espécies em sua composição e menor densidade, além de valores de cobertura diferentes dos outros dois estratos.

Apesar dessas características específicas de cada estrato analisado, de um modo geral, observou-se nos três estratos a predominância de espécies secundárias de caráter pioneiro, comprovando que o remanescente florestal em questão encontra-se em um estágio secundário de sucessão ecológica, por um processo exploratório no passado.

\section{REFERÊNCIAS}

BARDDAL, M. L.; RODERJAN, C. V.; GALVÃO, F.; CURCIO, G. R. Caracterização florística e fitossociológica de um trecho sazonalmente inundável de Floresta Aluvial, em Araucária, PR. Ciência Florestal, Santa Maria, v. 14, n. 2, p. 37-50, 2004.

CARVALHO, P. E. R. Espécies arbóreas brasileiras. Brasília: EMBRAPA Informações Tecnológica, 2003. 1039 p.

IURK, M. C.; SANTOS, E. P.; DLUGOSZ, F. L.; TARDIVO, R. C. Levantamento florístico de um fragmento de Floresta Ombrófila Mista Aluvial do Rio Iguaçu, município de Palmeira, PR. Floresta, Curitiba, v. 39, n. 3, p. 605-617, jul./ set. 2009.

KLAUBERG, C.; PALUDO, G. F.; BORTOLUZZI, R. L. C.; MANTONAVI, A. Florística e estrutura de um fragmento de Floresta Ombrófila Mista no Planalto Catarinense. Biotemas, Brasília, v. 23, n. 1, p. 35-47, 2010.

KOCH, Z.; CORRÊA, M. S. Araucária: a floresta do Brasil meridional. Curitiba: Olhar Brasileiro, 2002. 148 p.

KOZERA, C.; DITTRICH, V. A. de O.; SILVA, S. M. Fitossociologia do componente arbóreo de um fragmento de Floresta Ombrófila Mista Montana, Curitiba, PR, BR. Floresta, Curitiba, v. 36, n. 2, p. 225-237, maio/ago. 2006.

Cerne, Lavras, v. 19, n. 3, p. 365-372, jul./set. 2013 
RIVERA, H. A. H.; ROSOT, N. C.; ROSOT, M. A. D.; OLIVEIRA, Y. M. M. Análise florística e fitossociológica do componente arbóreo da Floresta Ombrófila Mista presente na Reserva Florestal Embrapa/Epagri, Caçador, SC, Brasil. Floresta, Curitiba, v. 39, n. 3, p. 485-500, jul./set. 2009.

RODERJAN, C. V.; GALVÃO, F.; KUNIYOSHI, Y. S.; HATSCHBACH, G. G. As unidades fitogeográficas do estado do Paraná. Ciência \&Ambiente, Santa Maria, v. 24, p. 75-92, jan./jun. 2002.

RONDON NETO, S. M.; KOZERA, C.; ANDRADE, R. R.; CECY, A. T.; HUMMES, A. P.; FRITZSONS, E.; CALDEIRA, M. V. W.; MACIEL, M. N. M.; SOUZA, M. K. F. Caracterização florística estrutural de um fragmento da Floresta Ombrófila Mista, em Curitiba, PR, Brasil. Floresta, Curitiba, v. 32, n. 1, p. 3-16, jan./jun. 2002.
SANQUETTA, C. R.; WATZLAWICK, L. F.; CÔRTE, A. P. D.; FERNANDES, L. A. V.; SIQUEIRA, J. D. P. Inventários florestais: planejamento e execução. 2. ed. Curitiba: MultiGraphic, 2009. 316 p.

SILVA, A. C. da; HIGUCHI, P.; AGUIAR, M. D. de; NEGRINI, M.; FERT NETO, J.; HESS, A. F. Relações florísticas e fitossociologia de uma floresta ombrófila mista montana secundária em Lages, Santa Catarina. Ciência

Florestal, Santa Maria, v. 22, n. 1, p. 193-206, jan./mar. 2012.

VIBRANS, A. C.; UHLMANN, A.; SEVEGNANI, L.; MARCOLIN, M.; NAKAJIMA, N.; GRIPPA, C. R.; BROGNI, E.; GODOY, M. B. Ordenação dos dados de estrutura da Floresta Ombrófila Mista partindo de informações do inventário florísticoflorestal de Santa Catarina: resultados de estudo-piloto. Ciência Florestal, Santa Maria, v. 18, n. 4, p. 511-523, out./dez. 2008.

Recebido: 15 de fevereiro de 2011; aceito: 20 de dezembro de 2012.

Cerne, Lavras, v. 19, n. 3, p. 365-372, jul./set. 2013 